\title{
MENINGKATKAN KESEHATAN JIWA DAN KEMANDIRIAN MAYARAKAT MELALUI PEMBENTUKAN KADER SEHAT JIWA DAN PELATIHAN TERAPI SEFT DI WILAYAH PUSKESMAS CIBEUREUM
}

\section{IMPROVING MENTAL HEALTH AND COMMUNITY INDEPENDENCE HROUGH THE ESTABLISHMENT OF A HEALTHY CADRE AND SEFT THERAPY TRAINING IN CIBEUREUM COMMUNITY HEALTH CENTRE TASIKMALAYA}

\author{
Ridwan Kustiawan, Yanti Cahyati*, Ida Rosdiana \\ Poltekkes Kemenkes Tasikmalaya, Tasikmalaya \\ *Email: yantinaufal@gmail.com \\ (Diterima 18-01-2021; Disetujui 17-03-2021)
}

\begin{abstract}
ABSTRAK
Masalah kesehatan jiwa merupakan salah satu masalah kesehatan yang memerlukan penanganan yang serius. Massalah kesehatan jiwa yang ada di masyarakat masih terhitung banyak dan memerlukan kerja sama dengan berbagai pihak terkait. Kader kesehatan jiwa yang berada di masyarakat sangat diperlukan untuk membantu mendeteksi dan mengatasi berbagai masalah kesehatan jiwa yang ada. Selain itu, masyarakat juga perlu berperan aktif dalam mengatasi masalah kesehatan jiwa serta bisa melakukan upaya kesehatan secara mandiri. Tujuan kegiatan pengabdian masyarakat ini adalah untuk meningkatkan pengetahuan masyarakat dan kader tentang upaya kesehatan jiwa dan upaya pemeliharaan kesehatan secara mandiri melalui pembentukan RW siaga sehat jiwa, deteksi dini keluarga sehat, keluarga berisiko masalah psikososial dan kelompok keluarga dengan gangguan jiwa di masyarakat. Kegiatan pengabdian masyarakat ini yang menjadi sasarannya adalah masyarakat dan kader di wilayah kerja Puskesmas Cibeureum yang merupakan daerah PKH di Kota Tasikmalaya. Metode kegiatan terdiri atas tahapan deteksi dini, pembentukan kades sehat jiwa dan penyuluhan kesehatan jiwa kepada masyarakat. Hasil kegiatan menunjukkan bahwa terbentuknya kader sehat jiwa yang terdiri atas 40 orang kader yang sudah dilatih melalui kegiatan pelatihan kader sehat jiwa. Deteksi dini masalah kesehatan jiwa dilaksanakan dengan melibatkan seluruh kader yang sebelumnya telah mengikuti kegiatan pelatihan kader sehat jiwa. Seluruh masyarakat bisa teridentifikasi kategorisasi dari kesehatan jiwa dengan menggunakan form deteksi yang ada. Masyarakat memahami secara lebih jelas tentang kesehatan jiwa masyarakat dan dapat mempraktekan metode seft dalam menghadapi masalahmasalah kesehatan secara mandiri.
\end{abstract}

Kata Kunci: PTM, Posbindu, sehat jiwa, seft terapi

\section{ABSTRACT}

Mental health problems are one of the health problems that require serious handling. There are still a lot of mental health masses in society and require cooperation with various related parties. Mental health cadres in the community are needed to help detect and overcome various mental health problems that exist. In addition, the community also needs to be active in overcoming mental health problems and be able to carry out health efforts independently. The purpose of this community service activity is to increase community and cadres knowledge about mental health efforts and health care efforts independently through the formation of mental health alert $R W$, early detection of healthy families, families at risk of psychosocial problems and family groups with mental disorders in the community. The community service activities that are targeted are the community and cadres in the Cibeureum Health Center working area, which is a PKH area in the City of Tasikmalaya. The activity method consists of early detection stages, the formation of a mentally healthy village head and mental health counseling to the community. Results shows that the formation of mental health cadres consisting of 40 cadres who have been trained through mental health cadre training activities. Early detection of mental health problems is carried out by involving all cadres who have previously participated in mental health cadre training activities. The entire community can identify the mental health categorization using the existing detection form. People understand more clearly about people's mental health and can practice the seft method in dealing with health problems independently.

Keywords: healthy cadre, seft therapy 
Meningkatkan Kesehatan Jiwa dan Kemandirian Mayarakat Melalui Pembentukan Kader Sehat Jiwa dan Pelatihan Terafi Seft di Wilayah Puskesmas Cibeureum

Ridwan Kustiawan, Yanti Cahyati, Ida Rosdiana

\section{LATAR BELAKANG}

Millenium Developmet Goals (MDGs) yang dideklarasikan pada September 2000 menyetujui agar semua negara termasuk Indonesia pada tahun 2015 mampu untuk: menanggulangi kemiskinan dan kelaparan, mencapai pendidikan dasar untuk semua, mendorong kesetaraan gender dan pemberdayaan perempuan, menurunkan angka kematian anak, meningkatkan kesehatan ibu, memerangi HIV/AIDS, malaria, dan penyakit menular lainnya, memastikan kelestarian lingkungan hidup, mengembangkan kemitraan global untuk pembangunan, namun pada akhir waktu yang telah ditetapkan, target capaian MDGs belum sesuai dengan yang diharapkan. Dari delapan tujuan MDGs di atas, poin 1, 4, 5, 6, dan 7 yang terkait langsung dengan masalah kesehatan misalnya, masih menyisakan persoalan besar yang harus dituntaskan.

Fenomena belum tuntasnya program MDGs dalam menyelesaikan masalah tidak hanya terjadi di Indonesia, tetapi terjadi secara menyeluruh di seluruh dunia, sehingga memunculkan target baru secara global pula yang merupakan kelanjutan atau penyempurnaan dari MDGs itu sendiri, yakni dengan adanya Sustainable Development Goals (SDGs) yang akan berlaku untuk 15 tahun ke depan yang dimulai pada tahun 2016 bagi negara-negara maju dan berkembang.

The Guardian menulis alasan mengapa SDGs akan jauh lebih baik dari MDGs, yakni: 1. SDGs lebih global dalam mengkolaborasikan program-programnya. MDGs sebelumnya dibuat oleh anggota negara OECD dan beberapa lembaga internasional. Sementara SDGs dibuat secara detail dengan negosiasi internasional yang juga terdiri atas negara berpendapatan menengah dan rendah. 2. Sekarang, sektor swasta juga akan memiliki peran yang sama, bahkan lebih besar. 3. MDGs tidak memiliki standar dasar hak asasi manusia (HAM). MDGs dianggap gagal untuk memberikan prioritas keadilan yang merata dalam bentuk-bentuk diskriminasi dan pelanggaran HAM, yang akhirnya berujung kepada masih banyaknya orang yang terjebak dalam kemiskinan. Sementara SDGs dinilai sudah didukung dengan dasar-dasar dan prinsip-prinsip HAM yang lebih baik. 4. SDGs adalah program inklusif. Tujuh target SDG sangat eksplisit tertuju kepada orang dengan kecacatan, dan tambahan enam target untuk situasi darurat, ada juga tujuh target bersifat universal dan dua target ditujukan untuk antidiskriminasi. 5. Indikator-indikator yang digunakan memberikan kesempatan untuk keterlibatan masyarakat sipil. 6. PBB dinilai bisa menginspirasi negara-negara di dunia dengan SDGs. Adapun salah satu target SDGs sampai dengan tahun 2030 adalah: mengurangi sepertiga kematian dini akibat penyakit 
tidak menular, melalui pencegahan dan pengobatan, dan mempromosikan kesehatan mental dan kebahagiaan.

Pengabdian kepada masyarakat ini menitikberatkan pada mengurangi seperti kematian dini akibat penyakit tidak menular dengan mempromosikan kesehatan mental. Menurut Riskesdas (2013), jumlah ganguan jiwa berat di Indonesia sekitar 1,7/mil dan Jawa Barat jumlah gangguan jiwa beratnya sebanyak 1,6\% mendekati rata-rata nasional dan gangguan emosionalnya 9,3\%, melebihi rata rata nasional yang hanya $6,0 \%$.

Langkah lebih lanjut Departemen Kesehatan telah merumuskan suatu visi dalam rangka mencapai tujuan tersebut. Visinya adalah "Masyarakat yang Mandiri Untuk Hidup Sehat", dengan Misi “Membuat Masyarakat Sehat". Strateginya antara lain menggerakkan dan memberdayakan masyarakat untuk hidup sehat, meningkatkan akses masyarakat terhadap pelayanan yang berkualitas, meningkatkan sistem surveilans, monitoring dan informasi kesehatan, serta meningkatkan pembiayaan kesehatan.

Desa Siaga merupakan gambaran masyarakat yang sadar, mau dan mampu mencegah dan mengatasi berbagai ancaman terhadap kesehatan masyarakat, seperti kurang gizi, kejadian bencana, termasuk didalamnya gangguan jiwa, dengan memanfaatkan potensi setempat secara gotong royong, menuju Desa Siaga. Desa Siaga Sehat Jiwa merupakan satu bentuk pengembangan dari pencanangan Desa Siaga yang bertujuan agar masyarakat ikut berperan serta dalam mendeteksi pasien gangguan jiwa yang belum terdeteksi, dan membantu pemulihan pasien yang telah dirawat di rumah sakit, serta siaga terhadap munculnya masalah kesehatan jiwa di masyarakat.

Tujuan kegiatan pengabdian masyarakat ini adalah untuk meningkatkan pengetahuan masyarakat dan kader tentang upaya kesehatan jiwa dan upaya pemeliharaan kesehatan secara mandiri melalui pembentukan RW siaga sehat Jiwa, deteksi dini keluarga sehat, keluarga berisiko masalah psikososial dan kelompok keluarga dengan gangguan jiwa di masyarakat, menggerakkan individu, keluarga dan kelompok sehat jiwa untuk mengikuti pendidikan kesehatan jiwa, menggerakkan keluarga dan kelompok yang mempunyai keluarga risiko masalah psikososial untuk mengikuti pendidikan kesehatan jiwa, menggerakkan keluarga dan kelompok yang mempunyai gangguan jiwa untuk mengikuti pendidikan kesehatan jiwa serta meningkatkan kemandirian masyarakat dalam memeliharan kesehatan. 
Meningkatkan Kesehatan Jiwa dan Kemandirian Mayarakat Melalui Pembentukan Kader Sehat Jiwa dan Pelatihan Terafi Seft di Wilayah Puskesmas Cibeureum

Ridwan Kustiawan, Yanti Cahyati, Ida Rosdiana

\section{BAHAN DAN METODE}

Kegiatan pengabdian masyarakat ini yang menjadi sasarannya adalah masyarakat dan kader di wilayah kerja Puskesmas Cibeureum yang merupakan daerah PKH di Kota Tasikmalaya. Sasarannya adalah kader dan msyarakat di wilayah Kelurahan Cibeureum Kecamatan Cibeureum Kota Tasikmalaya.

Kegiatan pengabdian masyarakat yang dilakukan meliputi kegiatan bina suasana, pendidikan kesehatan, dan advokasi. Langkah kegiatan yang dilakukan adalah:

1. Tahapan Persiapan

a. Mengidentifikasi masalah dan sasaran dengan studi pendahuluan.

b. Melakukan koordinansi dengan pihak Puskesmas Cibeureum.

c. Mempersiapkan tempat.

d. Mempersiapkan materi pre dan post test.

e. Mempersiapkan materi.

f. Mempersiapkan tim fasilitator dan narasumber.

g. Mempersiapkan sarana dan prasarana.

h. Menyusun rencana anggaran.

Kegiatan yang dilaksanakan meliputi kegiatan pembentukan kader sehat jiwa, identifikasi kategori kesehatan jiwa masyarakat dan penyuluhan kesehatan jiwa kepada masyarakat.

Metode kegiatan adalah pendidikan kesehatan dengan metode ceramah, tanya jawab, diskusi dan identifikasi. Kegiatan pengabdian masyarakat ini terdiri atas tiga kegiatan besar, yaitu kegiatan pelatihan kader sehat jiwa, kegiatan deteksi dni masalah kesehatan jiwa dan kegiatan penyuluhan kesehatan jiwa. Kegiatan pelatihan kader dilaksanakan dengan metode ceramah, Tanya jawab, dan role play. Kegiatan deteksi dini masalah kesehatan jiwa dilaksanakan oleh kader dengan metode melakukan wawancara dengan masyarakat terkait masalah kesehatan jiwa dengan menggunakan form yang sudah disediakan. Kegiatan penyuluhan kepada masyarakat tentang kesehatan jiwa dilaksanakan dengan metode ceramah dan Tanya jawab serta simulasi.

\section{HASIL DAN PEMBAHASAN}

\section{Pelatihan kader sehat Jiwa}

Kegiatan berjalan lancar dihadiri oleh seluruh kader yang diundang, sebanyak 38 orang. Hasil nilai post tes menunjukkan adanya peningkatan pengetahuan kader tentang kesehatan jiwa masyarakat. Pelatihan kader kesehatan jiwa merupakan hal penting dalam 
meningkatkan kesehatan jiwa masyarakat. Kegiatan ini akan memberikan output terbentuknya kader kesehatan jiwa di masyarakat yang merupakan ujung tombak kesehatan di masyarakat. Kader akan melaksanakan perannya terutama dalam mendeteksi dan mengenali gangguan jiwa yang terjadi di masyarakat untuk kemudian bekerja sama dengan petugas kesehatan di Puskesmas.

\section{Deteksi dini masalah kesehatan jiwa}

Kegiatan deteksi dini masalah kesehatan jiwa dilaksanakan dengan melibatkan kader. Seluruh masyarakat bisa teridentifikasi kategorisasi dari kesehatan jiwa dengan menggunakan form deteksi yang ada. Kegiatan ini merupakan hal penting, karena dapat terdeteksinya kategorisasi dari gangguan jiwa. Untuk masyarakat yang terdeteksi dengan kategori sehat jiwa maka tenaga kesehatan dapat mengoptimalisasi kesehatan masyaraat tersebut dengan lebih baik. Sedangkan untuk masarakat yang terdeteksi rawan gangguan jiwa perlu segera diintervensi dengan melibatkan tenaga kesehatan terkait.

\section{Penyuluhan kesehatan Jiwa}

Kegiatan penyuluhan kesehatan jiwa masyarakat dilaksanakan selama 2 kali dengan jumlah peserta yang hadir rata-rata 50 orang per kegiatan. Masyarakat memahami secara lebih jelas tentang kesehatan jiwa masyarakat dan dapat mempraktekan metode seft dalam menghadapi masalah-masalah kesehatan secara mandiri. SEFT merupakan pengembangan dari Emotional Freedom Technique (EFT) dimana faktor S adalah faktor Spiritual. Dalam intervensi EFT berfokus pada Self Centered yaitu asumsi kesembuhan berasal dari diri sendiri, sedangkan SEFT berasumsi bahwa kesembuhan berasal dari Tuhan (God Centered) (Zainudin, 2011).

Spiritual Emotional Freedom Technique (SEFT) merupakan suatu teknik yang menggabungkan unsur energi tubuh (energy medicine) dengan unsur terapi spiritualitas dan melakukan metode tapping pada beberapa titik tertentu pada tubuh (Zainudin, 2006). SEFT dikembangkan sesuai dengan sifat manusia. Hal ini dirancang untuk memenuhi sisi spiritual yang melekat pada setiap orang (Mulia et al, 2009).

Pasien dengan penyakit kronis sering mengalami gangguan psikologis yang sedikit banyak dipengaruhi oleh kondisi spiritual pasien (Lucette, et al, 2016). Pemenuhan kebutuhan spiritual sangat penting ketika sedang mengalami sakit fisik. Ketika kondisi fisik terganggu ada kemungkinan mengalami perubahan emosi, sehingga pada kondisi tersebut komponen spiritual seseorang sangat penting untuk mengatasi perubahan emosi 
Meningkatkan Kesehatan Jiwa dan Kemandirian Mayarakat Melalui Pembentukan Kader Sehat Jiwa dan Pelatihan Terafi Seft di Wilayah Puskesmas Cibeureum

Ridwan Kustiawan, Yanti Cahyati, Ida Rosdiana

tersebut. Mendekat pada Tuhan, diyakini akan memudahkan seseorang untuk mengatasi perubahan emosional dan rasa sakit selama sakit (Elham, 2015; Siddal, 2015; Loureiro, 2018).

Kegiatan penyuluhan dilaksanakan di Pesantren Al Khoeriyah dan Madrasah Al Ikhlas Cibeas. Penyuluhan kesehatan ini merupakan hal penting dalam meningkatkan kesehatan jiwa masyarakat. Selain itu, dengan kegiatan ini masyarakat akan diajarkan tentang tehnik pengelolaan masyarak kesehatan secara mandiri dengna metode seft.

Dalam pelaksanaan kegiatan pengabdian kepada masyarakat di wilayah kerja PKM Cibeureum terdapat faktor pendukung dan kendala yang ditemui. Faktor yang mendukung pelaksanaan pengabdian masyarakat ini diantaranya:

a. Dukungan dan kerjasama yang baik dari pihak puskesmas, baik kepala puskesmas maupun pemegang programnya, terutama pemegang program kesehatan jiwa.

b. Para kader yang antusias dalam setiap tahap kegiatan, mulai dari pelatihan kader, deteksi kesehatan jiwa di masyarakat dan koordinasi dalam pelaksanaan penyuluhan di masyarakat.

c. Masyarakat yang antusias dalam mengikuti kegiatan penyuluhan

Adapun kedala yang ditemui selama ini adalah dalam hal mengumpulkan masyarakat untuk penyuluhan tidak bisa berdasarkan klasifikasi gangguan jiwa, namun memanfaatkan sarana yang ada di masyarakat berupa kegiatan pengajian. Program tindak lanjut dari kegiatan ini diantaranya dengan terus melakukan koordinasi dengan pemegang program kesehatan jiwa PKM Cibeureum, dan melakukan pembinaan berkelanjutan kepada para kader kesehatan jiwa, dan mayarakat di wilayah kerja PKM Cibeureum terkait kesehatan jiwa.

\section{KESIMPULAN DAN SARAN}

Setelah dilakukan pelatihan kader di wilayah kerja Puskesmas Cibeureum Kota Tasikmalaya, ada beberapa hal yang dapat disimpulkan, yaitu:

1. Partispasi kader yang hadir cukup antusias dari yang ditargetkan $80 \%$ yang diundang hadir, dalam kenyataannya hadir 100\%.

2. Terjadi peningkatan pengetahuan dari nilai pre dan post test yaitu rata-rata nilai pre test 72 menjadi 85 untuk rata-rata nilai post test.

3. Ditemukannya kasus baru klien dengan gangguan jiwa yang sebelumnya belum tercatat di data puskesmas Cibeureum. 
Setelah dilakukan pelatihan kader mengenai kesehatan jiwa, diharapkan:

1. Kader

Dapat tetap mempraktekkan ilmu mengenai kesehatan jiwa, dengan tetap melakukan kegiatan kader sehat jiwa dan memberikan penyuluhan kepada masyarakatnya sesuai dengan klasifikasi gangguan kesehatan jiwa serta berkoordinasi dengan puskesmas.

2. Puskesmas

Mengadakan pembinaan berkelanjutan kepada kader dan masyarakat terkait kesehatan jiwa.

\section{UCAPAN TERIMA KASIH}

Ucapan terimakasih kami sampaikan kepada seluruh tim dari Poltekkes Kemenkes Tasikmalaya yang telah memfasilitasi kegiatan ini sehingga telaksana dengan lancar. Juga kepada pihak Puskesmas Cibeureum dan seluruh kader kesehatan wilayah Cibeueum.

\section{DAFTAR PUSTAKA}

Elham, H., Hazrati, M., Momennasab, M., \& Sareh, K. (2015). The effect of need-based spiritual/religious intervention on spiritual well-being and anxiety of elderly people. Holistic nursing practice, 29(3), 136-143.

Hidayat, Teddy. (2002)Masyarakat Dilarang Sakit Jiwa.htm. Pikiran Rakyat

Kep Menkes RI No. 564/Menkes/SK/VIII/2006, Pedoman Pelaksanaan Pengembangan Desa Siaga, Jakarta: Depkes.

Keliat, BA. (2005) .Modul Basic Course Community Mental Health Nursing. Jakarta :WHO.FIK UI

Ma'rifah, A. R., Handayani, R. N., \& Dewi, P. (2015). Pengaruh Pemberian Therapi Seft (Spiritual Emosional Freedom Tehnik) TERHADAP PENURUNAN NYERI POST OPERASI SEKSIO SESARIA Di RSUD MARGONO SOEKARDJO PURWOKERTO. Jurnal Ilmu Kesehatan (JIK) Bhamada, 6(2), 9-9.

Patterson, S. L. (2016). The effect of emotional freedom technique on stress and anxiety in nursing students: A pilot study. Nurse education today, 40, 104-110.

Tim CMHN (2002). Modul IC CMHN. Jakarta : Fakultas Ilmu Keperawatan UI

Videbeck, S.L. (2006). Psychiatric Mental Health Nursing. ( $3^{\text {rd }}$ edition). Philadhelpia: Lippincott Williams \& Wilkins. . (2008). Buku Ajar Keperawatan Jiwa. Alih Bahasa: Renata Komalasari, Afrina Hany, Jakarta: EGC 